\title{
Randomized equivalence study comparing the efficacy of 2 commercial internal teat sealants in dairy cows
}

\author{
S. M. Rowe, ${ }^{1 *} \odot$ S. M. Godden, ${ }^{1} \odot$ D. V. Nydam, ${ }^{2} \odot$ A. Lago, ${ }^{3} \odot$ A. K. Vasquez, ${ }^{2} \odot$ E. Royster, ${ }^{1}{ }^{\oplus}$ \\ and J. Timmerman ${ }^{1}$ \\ ${ }^{1}$ Department of Veterinary Population Medicine, University of Minnesota, St. Paul 55108 \\ ${ }^{2}$ Department of Population Medicine and Diagnostic Sciences, College of Veterinary Medicine, Cornell University, Ithaca, NY 14853 \\ ${ }^{3}$ Research and Development Department, DairyExperts, 1814 Rothschild Street, Tulare, CA 93274
}

\section{ABSTRACT}

The use of an internal teat sealant (ITS) at dry-off has been repeatedly shown to improve udder health in the subsequent lactation. However, almost all ITS research conducted in North America has evaluated one product (Orbeseal, Zoetis, Parsippany, NJ). The objective of this study was to evaluate a new ITS product (Lockout, Boehringer-Ingelheim Animal Health, Duluth, GA), by comparing it directly to Orbeseal in a multi-site, randomized, positively controlled equivalence trial for health indicators during the dry period [quarter-level new intramammary infection (IMI) risk, IMI cure risk, and IMI risk at 1 to $13 \mathrm{~d}$ in milk, DIM] and during the first 100 DIM [clinical mastitis and culling or death risk and test-day milk somatic cell count (SCC) and milk yield]. At dry-off, cows were randomly allocated to be treated with Orbeseal or Lockout after blanket administration of a cloxacillin dry cow therapy product. Cows were then followed from dry-off until 100 DIM. Intramammary infection status at enrollment and at 1 to 13 DIM was determined using standard bacteriological methods, allowing for the measurement of IMI dynamics during the dry period (i.e., IMI cures and new IMI). The effect of ITS group on dry period IMI cure, dry period new IMI, and IMI risk at 1 to 13 DIM was determined using generalized linear mixed models (logistic). Marginal standardization was used to derive risk difference estimates. An equivalence hypothesis test was conducted to compare ITS groups for dry period new IMI risk (margin of equivalence was $\pm 5 \%$ units). The effect of ITS group on clinical mastitis and culling or death was determined using Cox proportional hazards regression. The effect of ITS group on testday SCC and milk yield was determined using linear mixed models. Final models indicated that measures of quarter-level IMI dynamics were similar between ITS

Received November 10, 2019.

Accepted January 14, 2020.

*Corresponding author: samrowe101@gmail.com groups (i.e., risk difference estimates and 95\% confidence intervals all close to zero). Furthermore, Lockout was found to be equivalent to Orbeseal for dry period new IMI risk using an equivalence hypothesis test. Hazard ratio estimates for clinical mastitis and culling or death were close to 1 and differences in SCC and milk yield between ITS groups were close to 0, indicating negligible effects of ITS group on test-day SCC and milk yield. In most cases, these effect estimates were relatively precise (i.e., narrow 95\% confidence intervals). We conclude that producers using blanket dry cow therapy could consider including Orbeseal or Lockout treatment in their programs.

Key words: intramammary infection, dry cow therapy, teat sealant, mastitis

\section{INTRODUCTION}

Control of IMI during the dry period is necessary to optimize udder health in early lactation (Green et al., 2002). New IMI during the dry period can be prevented by establishing a barrier within the teat, which naturally occurs in most dairy cows, through the formation of a keratin plug within the teat canal. However, the keratin plug can take weeks to form and can be expelled from the teat in response to increased intramammary pressure in the late dry period, thus weakening the innate defensive capacity of the teat canal and rendering the quarter vulnerable to IMI (Dingwell et al., 2004). To overcome this challenge, producers often inject an internal teat sealant (ITS) into the teat canal and teat cistern of quarters at the time of dry-off to establish an immediate, robust barrier to pathogens. As inert pastes, ITS products have excellent persistence as barriers throughout the dry period (Kabera et al., 2018). Orbeseal (Zoetis, Parsippany, NJ; marketed as Teat Seal elsewhere) is a longstanding ITS product marketed in North America. It has been repeatedly shown that Orbeseal, containing $4 \mathrm{~g}$ of bismuth subnitrate paste (65\% weight for weight), can reduce new IMI risk during the dry period when used in combination with 
dry cow therapy (DCT) antibiotics or alone (Rabiee and Lean, 2013). Furthermore, this product has also been shown to reduce SCC and clinical mastitis risk in early lactation (Godden et al., 2003; Rabiee and Lean, 2013; Golder et al., 2016). Because of its demonstrated efficacy, the adoption of Orbeseal by US dairy herds has continued to increase since it was first validated in the region (Godden et al., 2003). However, new ITS products recently have entered the market. Increased competition among ITS products may reduce prices and thus benefit farmers. However, no rigorous scientific evidence is currently available to support the use of products other than Orbeseal. Consequently, the objective of this study was to evaluate a new ITS product (Lockout, Boehringer-Ingelheim Animal Health, Duluth, GA) by comparing it directly to Orbeseal in a multi-site, randomized, positively controlled equivalence clinical trial for health indicators during the dry period (quarter-level new IMI risk, IMI cure risk, IMI risk at 1 to 13 DIM) and during the first $100 \mathrm{~d}$ of lactation (risk of clinical mastitis and culling or death, and test-day milk SCC and milk yield).

\section{MATERIALS AND METHODS}

A randomized, controlled, natural exposure study of 2 ITS products in US dairy herds was conducted between June 2018 and April 2019. The Reporting Guidelines for Randomized Controlled Trials for Livestock and Food Safety (REFLECT; O'Connor et al., 2010) and Reporting of Noninferiority and Equivalence Randomized Trials Guidelines (Piaggio et al., 2006) were followed in the reporting of this study. Ethics approval was granted by the University of Minnesota Institutional Animal Care and Use Committee (Protocol \#1806-35991A).

\section{Study Herds}

Five herds were recruited from 3 study sites (New York $=1$ herd, Minnesota $=2$ herds, California $=2$ herds) from May to July of 2018. Herds were selected because they had a working relationship with the University of Minnesota, Cornell University, or DairyExperts Inc., had a herd size sufficiently large to dry off at least 15 cows per week, were on a monthly DHIA testing schedule (i.e., individual cow SCC and milk weight measurements), and routinely and consistently recorded clinical mastitis and culling events.

\section{Enrollment and Randomization}

Study technicians or investigators visited herds each week to enroll cows on the day of dry-off. Cows were eligible for enrollment if they had 3 or more functional quarters, had an expected dry period length of 30 to $90 \mathrm{~d}$, no recent antibiotic treatment (within $14 \mathrm{~d}$ ), no clinical mastitis (i.e., no visible abnormalities present in foremilk or heat, erythema or pain detected upon palpation of the udder), not lame [must be $<4 / 5$ on the Sprecher et al. (1997) scoring system] and not in poor body condition [must be $>1 / 5$ on the Edmonson et al. (1989) scoring system]. Duplicate, aseptic quarter-milk samples were collected from enrolled cows according to NMC guidelines (NMC, 2017). Briefly, after milking staff performed their usual pre-milking teat disinfection routine, study technicians, wearing clean disposable gloves, scrubbed teat ends with $70 \%$ isopropyl alcoholsoaked gauze swabs, discarded 3 squirts of foremilk, and sampled approximately 20 to $30 \mathrm{~mL}$ of milk into sterile 60 -mL vials. Samples were immediately chilled on ice and transported back to the site laboratory and stored at $-20^{\circ} \mathrm{C}$. At farms $\mathrm{A}, \mathrm{C}$, and $\mathrm{E}$, milk samples were collected postmilking because of logistical constraints when sampling cows on rotary parlors.

\section{Treatments}

At enrollment, cows were block-randomized (block size $=18$, number of unique blocks $=11$ ) into 2 groups, Orbeseal and Lockout, with the treatment group name indicating which ITS product would be used in enrolled quarters at the time of dry-off (i.e., Orbeseal, Zoetis; and Lockout, Boehringer-Ingelheim Animal Health, respectively). Block randomization ensures equal allocation to groups at a given enrollment time or place, which allowed us to stratify our randomization by herd and dry-off date. The sequence of treatment groups within each block was determined using a random number generator in Microsoft Excel (Microsoft Corp., Redmond, WA) that was printed onto the set of enrollment forms used at all sites. Block size of 18 was an arbitrary decision to accommodate the number of cows that could be fitted onto a single enrollment page, and it coincided with the approximate number of cows dried off on study dairies on any given week. We chose to use a reasonably large number of unique blocks $(\mathrm{n}=$ 11) to ensure equal enrollment of groups overall. All quarters were treated with an intramammary antibiotic containing $500 \mathrm{mg}$ of cloxacillin (Dry-Clox, BoehringerIngelheim Animal Health) before ITS infusion. Antibiotic and ITS infusions were administered after the final milking in the following fashion: study technicians or farm staff, wearing clean disposable gloves, scrubbed teat ends with $70 \%$ isopropyl alcohol-soaked gauze swabs for at least $5 \mathrm{~s}$ before the antibiotic treatment was infused into the mammary gland and again before ITS was infused into the teat cistern. A partial insertion technique was used for both antibiotic and ITS 
treatments. Study technicians administered antibiotic and ITS treatments on farms B, D, and E without help from herd workers. On farms A and C, antibiotic and ITS treatments were administered by study technicians and herd workers. Therefore, on those farms, herd workers were unmasked to treatment group.

\section{Follow-Up During the Dry Period and Postcalving}

On all farms, herd staff, who were primarily responsible for detecting clinical mastitis and other disease events during the dry period and early lactation, were not involved in the treatment of cows at dry-off, and therefore, masked to the treatment status of cows. However, it was possible for staff to determine treatment group of cows for first few milkings when ITS residues, colored white and blue, were present in foremilk. Duplicate, aseptic, quarter milk samples were collected by a study technician at 1 to 13 DIM. Premilking samples were collected for all herds except for farm C and E where samples were collected postmilking. Samples were immediately chilled on ice and transported back to the site laboratory for storage at $-20^{\circ} \mathrm{C}$. Somatic cell count and milk yield data were measured at monthly intervals as part of the herd's regular DHIA test schedule.

\section{Microbiological Culture of Milk Samples}

Milk samples were stored at $-20^{\circ} \mathrm{C}$ for 1 to $7 \mathrm{~d}$ before being cultured. The IMI status of each quarter at enrollment and at 1 to 13 DIM was determined using standard bacteriological methods. Milk culture was completed at the regional laboratory (Minnesota, New York, California) using culture methods that were standardized across the 3 laboratories. Laboratory staff were masked to treatment group. On the day of testing, milk samples were thawed at room temperature, homogenized by gentle inversion, and plated onto Trypticase soy agar with $5 \%$ sheep blood. Agar plates were inoculated with one loop-full (approximately 10 $\mu \mathrm{L}$ ) of sample using disposable plastic loops and incubated in aerobic conditions at $37 \pm 2^{\circ} \mathrm{C}$ for 42 to $48 \mathrm{~h}$. Only one sample from each quarter was cultured unless the first sample was contaminated. Samples were classified as contaminated if 3 or more isolates were recovered. At the regional laboratories in Minnesota and New York, all isolates were immediately identified using a MALDI-TOF MS (Microflex, Bruker Daltonics Inc., Billerica, MA). Peaks produced by each isolate were analyzed by the MALDI-TOF Biotyper reference library. The confidence level for each diagnosis reported by the software was used in the following fashion: $>2.0$, species level diagnosis recorded; 1.8-2, genus level diagnosis recorded; and $<1.8$, MALDI-TOF diagnosis not recorded and traditional biochemical identification methods used. Traditional identification methods included colony morphology, catalase reaction, gram stain, and cytology. Because the California laboratory did not have MALDI-TOF available for isolate identification, isolates identified there were stored in glycerol vials at $-80^{\circ} \mathrm{C}$ before submitting them to the Minnesota laboratory. Isolates sent to Minnesota were cultured on Trypticase soy agar with $5 \%$ sheep blood in aerobic conditions and at $37 \pm 2^{\circ} \mathrm{C}$ for $24 \mathrm{~h}$ before being identified using the same methods described earlier. If the culture from a glycerol vial failed to yield a single isolate (i.e., no growth or 2 or more isolates), then the original milk sample was cultured again in California and the isolate was resubmitted. If no pathogen was isolated on the second milk culture at the California laboratory, then the quarter was excluded from analysis. To improve the specificity of IMI classification (i.e., reduce false positives), non-aureus Staphylococcus spp. (NAS) isolates with less than 2 colonies ( $<200 \mathrm{cfu} /$ $\mathrm{mL}$ ) and Bacillus spp. isolates with less than 5 colonies $(<500 \mathrm{cfu} / \mathrm{mL})$ were reclassified as "no growth" and the quarter was considered uninfected (Dohoo et al., 2011b). This adjustment was made because poor specificity is a more potent source of biased measures of association than poor sensitivity (Haine et al., 2018).

\section{Statistical Analysis}

Sample Size Calculation. Sample size was calculated to enable an equivalence hypothesis test for the effect of ITS on dry period new IMI risk. We assumed that $20 \%$ of quarters would develop a new IMI during the dry period (Johnson et al., 2016). The margin of equivalence, $\alpha$ and power were set at $\pm 5,2.5$, and $80 \%$, respectively. The sample size required, according to these assumptions, was multiplied by 1.25 to account for clustering within the data and to account for missing new IMI statuses, due to contamination of milk samples or failure to collect a milk sample within 13 $\mathrm{d}$ of calving. Consequently, our objective was to enroll 1,682 quarters (approximately 420 cows) per group.

Variable Management. Cow- and quarter-level enrollment and dry-off treatment records, herd demographic information, and laboratory findings were recorded in spreadsheets (Google Sheets, Mountain View, CA). Disease events (clinical mastitis, culling, and death) and monthly SCC and milk yield records from monthly DHIA testing were extracted from electronic farm records. Data were imported into the R Statistical Programming Environment (R Core Team, 2018) for merging and cleaning. Analysis was conducted in $\mathrm{R}$ and Stata (version 15; StataCorp, College Station, TX). The data set and analyses can be downloaded at 
https://samrowe101.github.io/ITS2019/. No imputation methods were used for any variables. Normality of continuous variables was assessed by visualizing normal quantile-quantile plots. All SCC measures were $\log _{\mathrm{e}}$ transformed for analysis [i.e., $\log _{\mathrm{e}} \mathrm{SCC}=\log _{\mathrm{e}}$ (cells per $\mathrm{mL} / 1,000+1)]$. Cows and quarters were retrospectively excluded from analysis if they failed to meet inclusion criteria. Consequently, cows with a dry period outside of the 30 to $90 \mathrm{~d}$ range, including cows that failed to calve or were culled during the dry period, were excluded from analysis. Cows that died or were culled between enrollment and calving were excluded from all analyses. Furthermore, treatment records were used to retrospectively exclude quarters from cows with antibiotic treatment during the 14-d period before enrollment. Cows with antibiotic treatments (intramammary or parenteral with milk withholds) during the 14-d period before the postcalving sampling were excluded from quarter-level dry period IMI dynamics outcomes, but not postcalving outcomes at the cow level such as clinical mastitis risk. Quarters without a determined IMI status, mostly due to contamination of milk samples, were excluded from analysis.

\section{Effect of ITS Group on Quarter-Level Dry Period IMI Dynamics}

Intramammary infection status at enrollment and at 1 to 13 DIM was used to determine dry period IMI dynamics, including IMI cure and dry period new IMI. Consequently, quarters missing an IMI status at one or both periods were not assigned a value for dry period cure or new IMI. Only quarters with an IMI at the enrollment sample were considered at risk for a dry period IMI cure. Dry period IMI cure cases were defined as a quarter with an IMI at enrollment caused by an isolate that was not diagnosed at the postcalving sampling. All quarters were considered at risk for developing a dry period new IMI. Dry period new IMI cases were defined as a quarter with a species-level IMI at calving that was not originally present in the enrollment sample. For example, a quarter with a Staphylococcus chromogenes IMI at enrollment and no growth at 1 to 13 DIM would be coded as a dry period IMI cure $=1$, and dry period new IMI $=0$. A quarter with a Staphylococcus chromogenes IMI at enrollment and a Staphylococcus haemolyticus IMI at 1 to 13 DIM would be coded as a dry period IMI cure $=1$ and a dry period new IMI $=1$. Isolates were matched at the genus level if the species was not known. For example, a quarter with a Staphylococcus chromogenes IMI at enrollment and a Staphylococcus sp. IMI at 1 to 13 DIM would be coded as a dry period IMI cure $=0$, and dry period new IMI $=0$.
Risk ratio estimates from univariable models for the relationship between explanatory variables of interest and IMI at enrollment, IMI at 1 to 13 DIM, dry period cure risk, and dry period new IMI risk were calculated using generalized linear models (binomial family, log link; also known as log-binomial model). Log-binomial models were used instead of logistic models (i.e., logit link) because they allow for direct estimation of risk ratios, which are more intuitive than odds ratios. Potential cow-level confounders investigated included: age at enrollment (mo), parity at enrollment $(1,2,3, \geq 4)$, milk yield at the most recent DHI test-day before enrollment $(\mathrm{kg}), \log _{\mathrm{e}} \mathrm{SCC}$ at the most recent test-day before enrollment (log cells $\left.\times 10^{3} / \mathrm{mL}\right)$, peak $\log _{\mathrm{e}} \mathrm{SCC}$ during the lactation of enrollment, any clinical mastitis events during the lactation of enrollment (dichotomous), DIM at dry-off (per $10 \mathrm{~d}$ ), and DIM at postcalving milk sample (d). In addition, quarter-level IMI at enrollment (dichotomous) was considered a potential confounder for the relationship between treatment group and dry period new IMI and IMI risk postcalving.

The final multivariable models for the effect of treatment group on quarter-level, IMI-based outcomes (dry period cure risk, dry period new IMI risk, IMI risk at 1 to 13 DIM) were determined using generalized linear mixed models (binomial family, logit link; also known as logistic regression). A logit link was used instead of a log link (as was used for the univariable analysis) because generalized linear mixed models do not currently accommodate log links in $\mathrm{R}$ or Stata. However, the effect estimates from the logistic model were converted to risk differences (RD), using a process called marginal standardization in Stata (Muller and MacLehose, 2014). We chose to report RD instead of odds ratios because $\mathrm{RD}$ are better suited to equivalence hypothesis testing and because they are more intuitive than relative measures.

Multivariable models were built using the following strategy: a directed acyclic graph was drawn for each model to identify potential confounders. Correlations between potential confounders were determined using Pearson correlation coefficient and Kendall's tau for normally and nonnormally distributed continuous variables, respectively. Highly correlated variables $(>0.7)$ were not offered into the same model; the more suitable variable was chosen based on missing values, reliability of measurement, or biological plausibility. Potential confounders were simultaneously offered into the initial model. Following this, biologically plausible effectmeasure modification on the multiplicative scale was evaluated by fitting interaction terms as fixed effects. For interaction terms with Wald tests at $P<0.05$, effect estimates were stratified by the effect-modifying variable, and if biologically relevant, were included in 
the final model. Interaction terms were removed from the model if they had Wald tests at $P>0.05$ or if they did not add subjective explanatory value to the model. Following this, covariates (potential confounders) were removed from the model one step at a time, and replaced back into the model if removal changed the effect estimate by more than 10\% (Greenland and Pearce, 2015). All models included random intercepts for cow and herd to account for the clustering of quarters within cows, and cows within herds.

An equivalence hypothesis test was used to evaluate the effect of ITS group on quarter-level dry period new IMI risk, using the confidence interval approach, with an a priori margin of equivalence specified at $\pm 5 \%$. Therefore, the null hypothesis was that the risk of new IMI in the Lockout group was either $\leq-5 \%$ or $\geq+5 \%$ units than in Orbeseal quarters (i.e., $\mathrm{RD} \leq-0.05$ or $\geq 0.05$ ). The 2 -sided, $95 \%$ confidence interval for the $\mathrm{RD}$ was used to conduct the hypothesis test, such that if the lower and upper limits of the $95 \%$ confidence interval were contained within the lower and upper margins of equivalence, then risk of new IMI in Lockout quarters would be considered equivalent to risk in Orbeseal quarters. No superiority hypothesis tests were conducted (Wasserstein and Lazar, 2016).

\section{Effect of ITS Group on Clinical Mastitis and Culling/ Death During the First 100 Days of Lactation}

Survival analysis was conducted to determine the effect of ITS group on clinical mastitis and culling and death during the first $100 \mathrm{~d}$ of lactation. Clinical mastitis cases were defined as the first case of clinical mastitis from calving until 100 DIM. Cows were left-censored (excluded) if they had died or been culled before calving. Cows with clinical mastitis events during the dry period were considered at risk for clinical mastitis from 1 to 100 DIM. Cows were right-censored at 100 DIM or at culling or death. Culling or death events were defined as any record of death or culling in farm records. Decisions to cull the animal in the future (e.g., "do not breed" or "DNB") were not considered as a culling event. Kaplan-Meier survival curves were generated, with the log-rank test used to compare between treatment groups. Hazard ratios (HR) were estimated using Cox proportional hazards regression, using a robust sandwich estimator to account for the clustering of cows within herds. The proportional hazards assumption for each covariate was assessed by visualizing Schoenfeld residuals against time and using the Schoenfeld test. Covariates with hazards shown to vary over time $(\beta \neq 0, P<0.05)$ were stratified to allow for multiple baseline hazards. The Efron approxi- mation method was used to deal with tied observations. Risk ratio estimates from univariable models for the relationship between explanatory variables of interest and 100-d clinical mastitis risk and culling or death risk were calculated using generalized linear models (log-binomial). The same potential confounder list and model building strategy for dry period IMI dynamics were used in creating final Cox proportional hazards models for the effect of ITS group on clinical mastitis and culling.

\section{Effect of ITS Group on Milk Yield and SCC During the First 100 Days of Lactation}

The effect of ITS group on monthly test-day $\log _{\mathrm{e}}$ transformed SCC and milk yield data were analyzed using linear mixed models. Random intercepts for cow and herd were used to account for the clustering of tests within cows, and cows within herds. The DIM of the DHIA test was forced into the model as a fixed effect (levels: 0-20, 21-40, 41-60, 61-80, 81-100 DIM). Effect estimates from univariable models for the relationship between explanatory variables of interest and outcome variables (i.e., SCC and milk yield) were calculated using linear models. The same potential confounder list and general model building strategy for dry period IMI dynamics was used in creating final linear mixed models for the effect of ITS group on SCC and milk yield. Assumptions of homoscedasticity and normality of residuals were evaluated using residual scatter plots and normal quantile-quantile plots. Estimated marginal means ( least squares means) on the log and linear (i.e., geometric means) scales were used to compare between treatment groups.

\section{RESULTS}

\section{Enrollment}

Demographic descriptors of cows from the 5 study herds are summarized in Table 1. Herd size ranged from 1,050 to 9,200 milking cows and bulk milk SCC before enrollment ranged from 145,000 to 230,000 cells/ $\mathrm{mL}$. All herds routinely practiced pre- and postmilking teat disinfection as part of their milking routine and used a registered Escherichia coli vaccine as part of their mastitis control strategy. At enrollment, cows were randomly allocated to Orbeseal $(\mathrm{n}=446)$ and Lockout $(\mathrm{n}=456)$ groups. No meaningful differences in measured demographics were observed between ITS groups, indicating that randomization effectively balanced treatment groups for potential confounders at baseline (Table 2). 
Table 1. Comparison of study herds for herd and cow-level characteristics at enrollment of a clinical trial comparing the use of 2 internal teat sealants at dry-off ${ }^{1}$

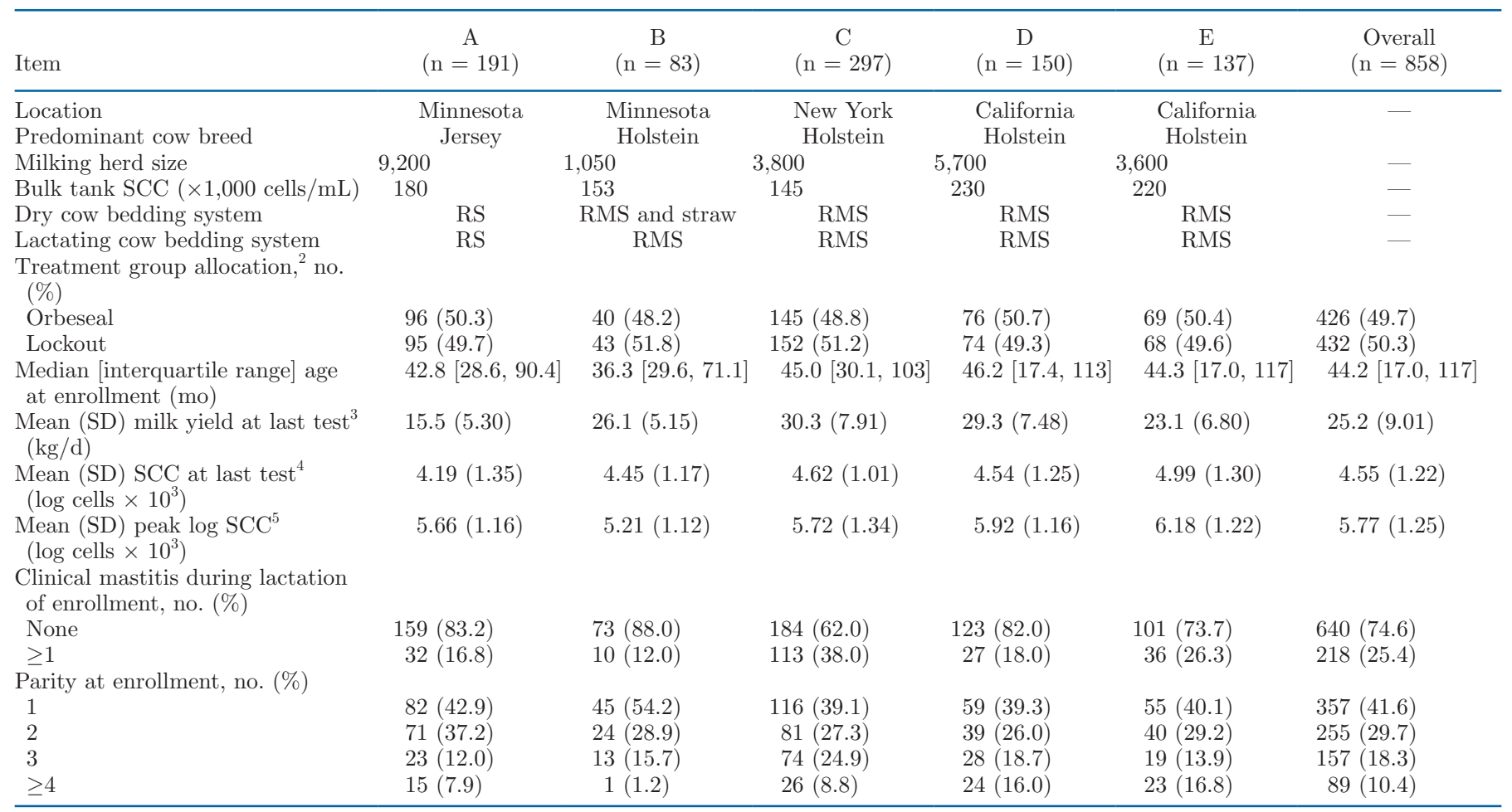

${ }^{1} \mathrm{RS}=$ reclaimed sand; RMS = manure solids

${ }^{2}$ Orbeseal (Zoetis, Parsippany, NJ) and Lockout (Boehringer-Ingelheim Animal Health, Duluth, GA).

${ }^{3}$ Milk yield at the most recent herd test before enrollment.

${ }^{4}$ Somatic cell count at the most recent herd test before enrollment.

${ }^{5}$ Highest $\log$ SCC at any point during the lactation of enrollment.

\section{Loss to Follow-Up}

Cow- and quarter-level exclusions during each phase of the study are outlined in Figure 1. Loss to follow- up was very similar between treatment groups during all phases. Most precalving exclusions (44 of 68) occurred immediately following randomization. In most cases, this was because screening of cows for clinical

Table 2. Comparison of treatment groups for cow-level characteristics at enrollment of a clinical trial comparing the use of 2 internal teat sealants at dry-off ${ }^{1}$

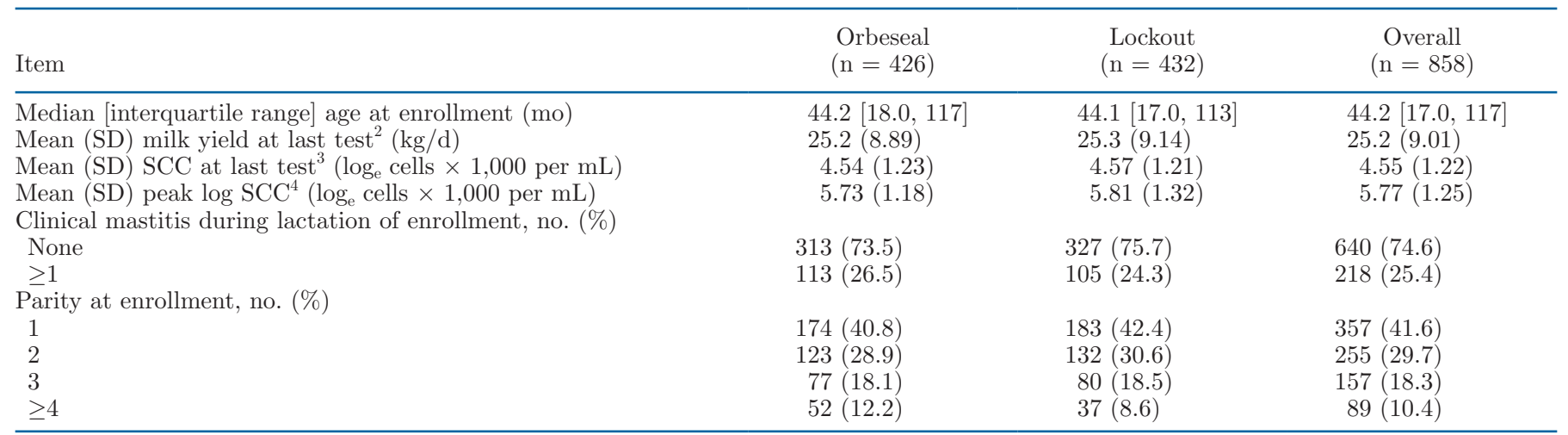

${ }^{1}$ Orbeseal (Zoetis, Parsippany, NJ) and Lockout (Boehringer-Ingelheim Animal Health, Duluth, GA).

${ }^{2}$ Milk yield at the most recent herd test before enrollment.

${ }^{3}$ Somatic cell count at the most recent herd test before enrollment.

${ }^{4}$ Highest $\log _{\mathrm{e}} \mathrm{SCC}$ at any point during the lactation of enrollment. 


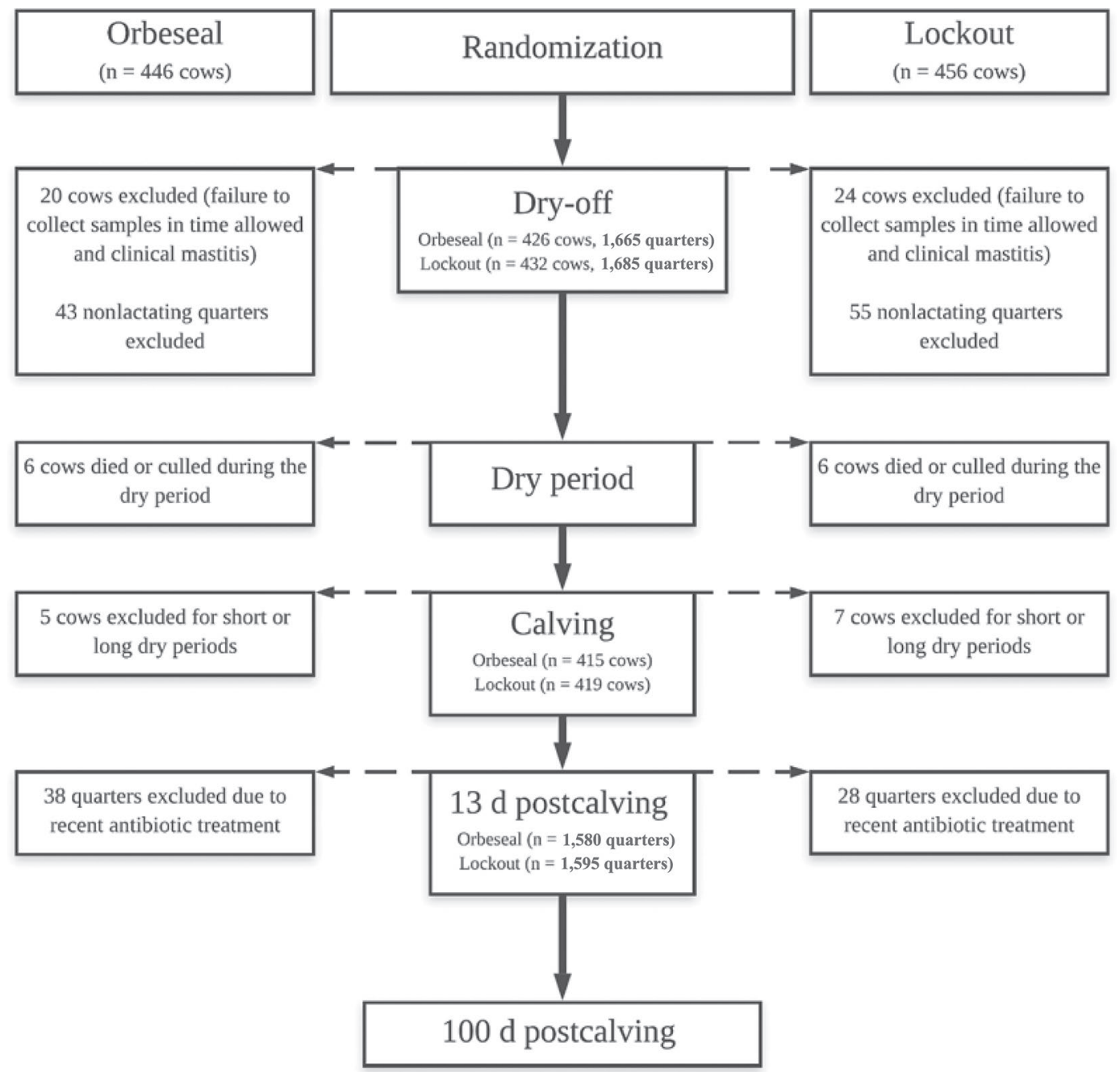

Figure 1. Description of losses to follow-up during each stage of the trial. Exclusions for the Orbeseal (Zoetis, Parsippany, NJ) and Lockout (Boehringer-Ingelheim Animal Health, Duluth, GA) groups are shown in boxes to the left and right sides of each phase of the study, respectively. At each phase, the number of enrolled cows or quarters are shown, depending on what unit is used for the analysis for follow-up during that phase.

mastitis and temperament (i.e., being able to enroll, sample, and treat cows in a safe and timely manner) was not possible before randomization in some herds. Consequently, most of these cows were excluded before sampling or treatment had occurred. Four cows were retrospectively excluded for recent $(<14 \mathrm{~d})$ antibiotic therapy. The remaining precalving exclusions occurred during the dry period, which were due to culling or death $(\mathrm{n}=12)$ or failure to have a 30 - to 90 -d dry period $(\mathrm{n}=12)$. Culling and death events during the dry period were the same between treatment groups (n $=6$ each). Quarters with contaminated milk samples at dry-off $(5 \%)$ or at 1 to 13 DIM $(7 \%)$ had missing values for IMI status, and thus were excluded from analysis of quarter-level outcomes. Recent $(<14 \mathrm{~d})$ antibiotic treatment (mostly for reproductive infections and lameness) caused an additional 66 quarters to be excluded from quarter-level analyses. The final numbers of quarters considered at risk of having an IMI at 1 to 13 DIM for each group were Orbeseal $(\mathrm{n}=1,382)$ and Lockout ( $\mathrm{n}$ $=1,425)$. The final number of cows at risk for clinical mastitis and culling were Orbeseal $(\mathrm{n}=415)$ and Lockout $(\mathrm{n}=419)$.

\section{IMI at Dry-Off and at 1 to 13 DIM}

The overall crude quarter-level prevalence of IMI at dry-off was $22 \%(663 / 3,010$, Table 3$)$, and was similar in the Orbeseal (21.1\%) and Lockout (22.9\%) groups. The prevalences of each pathogen group were NAS (15.7\%), Staphylococcus aureus (0.4\%), Streptococcus spp. and Streptococcus-like organisms (2.3\%), other 
gram-positive bacteria (3.9\%), gram-negative bacteria $(0.5 \%)$, and other pathogens $(0.1 \%)$. The most common bacterial species was Staphylococcus chromogenes, which infected $10.8 \%$ of all quarters. Other common causes of IMI at enrollment included Staphylococcus spp. (3.0\%), Bacillus spp. (2.1\%), Staphylococcus haemolyticus (1.2\%), and Streptococcus uberis (0.9\%). Staphylococcus aureus (0.4\%), and coliforms (0.2\%) were uncommon causes of IMI.

The overall crude quarter-level prevalence of IMI at 1 to 13 DIM was $12.8 \%(358 / 2,807$, Table 4$)$, and was similar in Orbeseal (13.5\%) and Lockout (12.0\%)

Table 3. Quarter-level prevalence of IMI in 858 cows, sampled on the day of dry-off for a clinical trial comparing the use of 2 internal teat sealants ${ }^{1}$

\begin{tabular}{|c|c|c|c|c|c|c|}
\hline \multirow[b]{2}{*}{ Item } & \multicolumn{2}{|c|}{ Orbeseal } & \multicolumn{2}{|c|}{ Lockout } & \multicolumn{2}{|c|}{ All quarters } \\
\hline & No. & $\%$ & No. & $\%$ & No. & $\%$ \\
\hline Quarters sampled at dry-off & 1,665 & 100.0 & 1,685 & 100.0 & 3,350 & 100.0 \\
\hline Quarters excluded & 85 & 5.1 & 90 & 5.3 & 175 & 5.2 \\
\hline Quarters contaminated at dry-off & 66 & 4.0 & 62 & 3.7 & 165 & 4.9 \\
\hline $\mathrm{CA}$ isolate undetermined ${ }^{2}$ & 13 & 0.8 & 24 & 1.4 & 37 & 1.1 \\
\hline Quarters at risk & 1,501 & 100.0 & 1,509 & 100.0 & 3,010 & 100.0 \\
\hline No growth & 1,184 & 74.9 & 1,163 & 72.5 & 2,347 & 78.0 \\
\hline Infected quarters & 317 & 21.1 & 346 & 22.9 & 663 & 22.0 \\
\hline Single pathogen & 295 & 19.7 & 330 & 21.9 & 625 & 20.8 \\
\hline Mixed infection & 22 & 1.5 & 16 & 1.1 & 38 & 1.3 \\
\hline Gram positive & 309 & 20.6 & 337 & 22.3 & 646 & 21.5 \\
\hline Staphylococcus aureus & 4 & 0.3 & 7 & 0.5 & 11 & 0.4 \\
\hline Non-aureus Staphylococcus spp. & 228 & 15.2 & 246 & 16.3 & 474 & 15.7 \\
\hline Staphylococcus chromogenes & 156 & 10.4 & 169 & 11.2 & 325 & 10.8 \\
\hline Staphylococcus epidermidis & 1 & 0.1 & 0 & 0.0 & 1 & 0.0 \\
\hline Staphylococcus haemolyticus & 18 & 1.2 & 18 & 1.2 & 36 & 1.2 \\
\hline Staphylococcus hominis & 3 & 0.2 & 0 & 0.0 & 3 & 0.1 \\
\hline Staphylococcus sciuri & 1 & 0.1 & 10 & 0.7 & 11 & 0.4 \\
\hline Staphylococcus simulans & 5 & 0.3 & 8 & 0.5 & 13 & 0.4 \\
\hline Staphylococcus xylosus/saprophyticus & 3 & 0.2 & 5 & 0.3 & 8 & 0.3 \\
\hline Staphylococcus sp. & 47 & 3.1 & 43 & 2.8 & 90 & 3.0 \\
\hline Streptococcus spp. and Streptococcus-like species & 33 & 2.2 & 37 & 2.5 & 70 & 2.3 \\
\hline Enterococcus saccharolyticus & 1 & 0.1 & 2 & 0.1 & 3 & 0.1 \\
\hline Enterococcus spp. & 3 & 0.2 & 2 & 0.1 & 5 & 0.2 \\
\hline Lactococcus garvieae & 7 & 0.5 & 6 & 0.4 & 13 & 0.4 \\
\hline Lactococcus spp. & 0 & 0.0 & 2 & 0.1 & 2 & 0.1 \\
\hline Streptococcus dysgalactiae & 4 & 0.3 & 2 & 0.1 & 6 & 0.2 \\
\hline Streptococcus uberis & 10 & 0.7 & 16 & 1.1 & 26 & 0.9 \\
\hline Streptococcus sp. & 8 & 0.5 & 7 & 0.5 & 15 & 0.5 \\
\hline Other gram positive & 60 & 4.0 & 56 & 3.7 & 116 & 3.9 \\
\hline Arthrobacter spp. & 2 & 0.1 & 1 & 0.1 & 3 & 0.1 \\
\hline Bacillus spp. & 32 & 2.1 & 32 & 2.1 & 64 & 2.1 \\
\hline Corynebacterium spp. & 17 & 1.1 & 10 & 0.7 & 27 & 0.9 \\
\hline Micrococcus sp. & 3 & 0.2 & 3 & 0.2 & 6 & 0.2 \\
\hline Trueperella pyogenes & 0 & 0.0 & 3 & 0.2 & 3 & 0.1 \\
\hline Gram-positive coccus & 2 & 0.1 & 3 & 0.2 & 5 & 0.2 \\
\hline Gram-positive rod & 4 & 0.3 & 4 & 0.3 & 8 & 0.3 \\
\hline Gram-negative & 8 & 0.5 & 7 & 0.5 & 15 & 0.5 \\
\hline Coliform & 3 & 0.2 & 3 & 0.2 & 6 & 0.2 \\
\hline Enterobacter spp. & 1 & 0.1 & 0 & 0.0 & 1 & 0.0 \\
\hline Escherichia coli & 0 & 0.0 & 1 & 0.1 & 1 & 0.0 \\
\hline Klebsiella oxytoca & 0 & 0.0 & 1 & 0.1 & 1 & 0.0 \\
\hline Klebsiella pneumoniae & 2 & 0.1 & 1 & 0.1 & 3 & 0.1 \\
\hline Other gram negative & 5 & 0.3 & 4 & 0.3 & 9 & 0.3 \\
\hline Acinetobacter spp. & 2 & 0.1 & 1 & 0.1 & 3 & 0.1 \\
\hline Pseudomonas aeruginosa & 1 & 0.1 & 2 & 0.1 & 3 & 0.1 \\
\hline Gram-negative organism & 2 & 0.1 & 1 & 0.1 & 3 & 0.1 \\
\hline \multicolumn{7}{|l|}{ Other } \\
\hline Yeast & 0 & 0.0 & 2 & 0.1 & 2 & 0.1 \\
\hline
\end{tabular}

${ }^{1}$ Orbeseal (Zoetis, Parsippany, NJ) and Lockout (Boehringer-Ingelheim Animal Health, Duluth, GA).

${ }^{2}$ Quarters where samples exhibited growth at the California laboratory, but isolates were not identified at the Minnesota laboratory. 
Table 4. Quarter-level prevalence of IMI in 834 cows, sampled 1 to $13 \mathrm{~d}$ postcalving for a clinical trial comparing the use of 2 internal teat sealants ${ }^{1}$

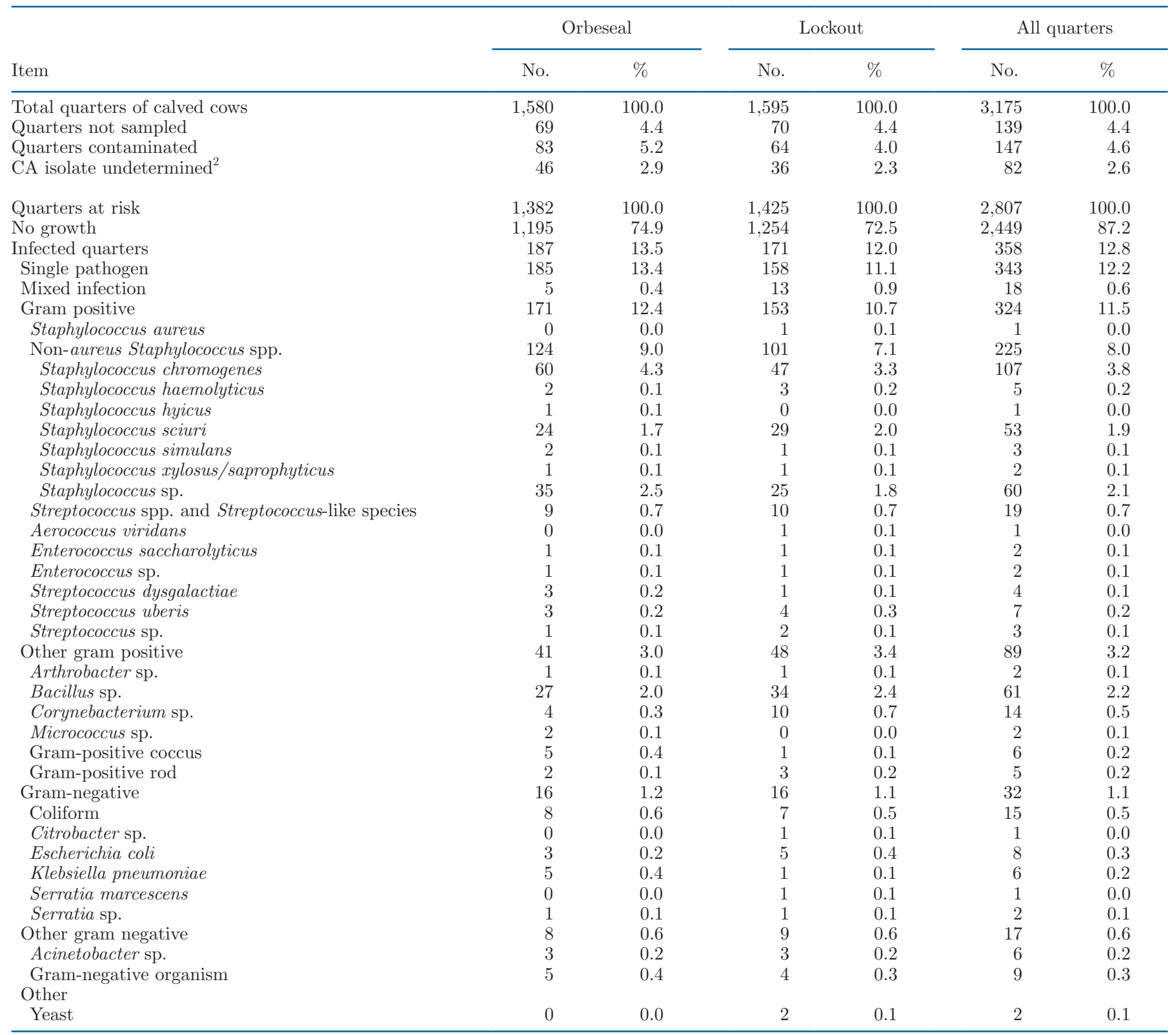

${ }^{1}$ Orbeseal (Zoetis, Parsippany, NJ) and Lockout (Boehringer-Ingelheim Animal Health, Duluth, GA).

${ }^{2}$ Quarters where samples exhibited growth at the California laboratory, but isolates were not identified at the Minnesota laboratory.

groups. Risk ratio estimates from 10 univariable models for potential predictors of IMI risk at 1 to 13 DIM are shown in Supplemental Table S1 (https://doi .org/10.3168/jds.2019-17884). The final generalized linear mixed model found that Lockout quarters had a similar adjusted IMI risk at 1 to 13 DIM (14.1\%) to Orbeseal quarters $(16.0 \%, \mathrm{RD}:-1.9 \%, 95 \% \mathrm{CI}$ : $-5.0,1.2 \%)$. The intraclass correlation coefficients for clustering of quarters within cows, and cows within herds were 0.32 and 0.16 . The prevalences of each pathogen group were NAS (8.0\%), Streptococcus spp. and Streptococcus-like organisms (0.7\%), other gram-positive bacteria $(3.2 \%)$, gram-negative bacteria $(1.1 \%)$, and other pathogens $(0.1 \%)$. Common bacterial causes of IMI at 1 to 13 DIM included Staphylococcus chromogenes (3.8\%), Staphylococcus spp. (2.1\%), Bacillus spp. (2.2\%), and Staphylococcus sciuri $(1.9 \%)$. 


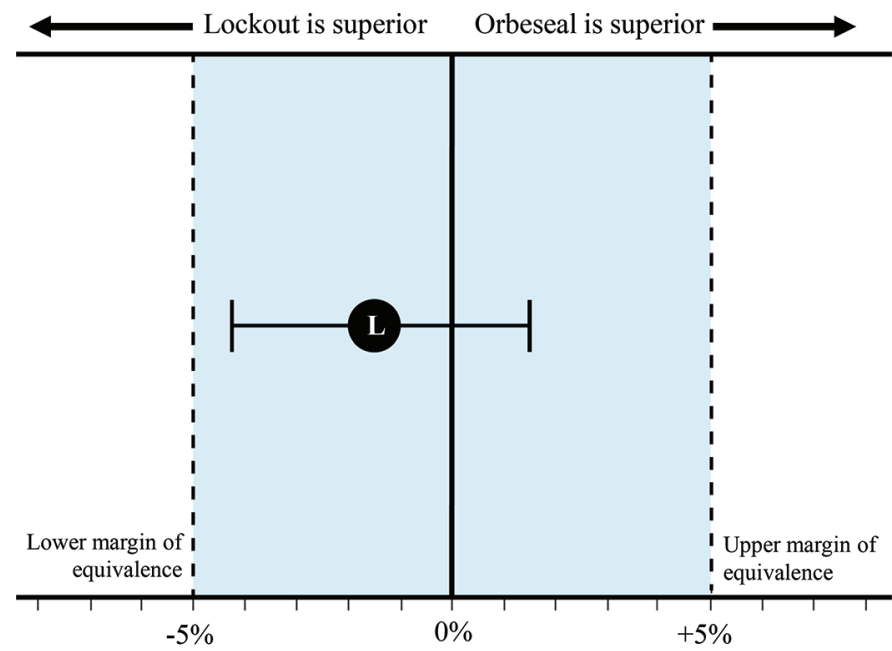

Difference in new IMI risk

Figure 2. Equivalence hypothesis test for the effect of using Lockout (L; Boehringer-Ingelheim Animal Health, Duluth, GA) at dry-off on dry period new IMI risk, as compared with using Orbeseal (Zoetis, Parsippany, NJ). Adjusted dry period new IMI risk in the Orbeseal group was $13.8 \%$, indicated by the solid vertical line. An upper and lower margin of equivalence of $\pm 5 \%$ was specified a priori, which is indicated by the dashed vertical lines. The lower and upper limits of the 2-sided 95\% CI for the risk difference (cf. Orbeseal) of new IMI risk was within the margin of equivalence, indicating that Lockout (new IMI risk $=12.4 \%$ ) performed as well as Orbeseal.

\section{Effect of ITS Group on Dry Period New IMI Risk and IMI Cure Risk}

The crude dry period new IMI risk for all quarters was $11.0 \%(293 / 2,664)$, which was similar in Lockout (10.4\%) and Orbeseal (11.6\%) quarters. Risk ratio esti- mates from 10 univariable models for potential predictors of dry period new IMI and IMI cure are shown in Supplemental Table S1 (https://doi.org/10.3168/jds .2019-17884). The final generalized linear mixed model found that Lockout quarters had a similar adjusted dry period new IMI risk to Orbeseal quarters (12.4 vs. $13.8 \%$, respectively; RD: $-1.4 \%, 95 \%$ CI: $-4.3,1.6 \%$, Table 5). The $95 \%$ CI for RD estimates for dry period new IMI were within our a priori margin of equivalence $(-5.0$ and $+5.0 \%$ units), indicating that Lockout is equivalent to Orbeseal for this outcome (Figure 2). The intraclass correlation coefficients for clustering of quarters within cows, and cows within herds were 0.29 and 0.14. The overall crude quarter-level new IMI risk for each herd ranged from 3.6 to $26.4 \%$. Most of the 293 new IMI identified in this study were caused by NAS $(59.4 \%)$ and other gram-positive bacteria (28.0\%; Supplemental Table S2, https://doi.org/10.3168/jds.2019 -17884). The most common species causing new IMI were S. chromogenes (30.4\%), Bacillus spp. (19.1\%), S. sciuri (13.7\%), and Staphylococcus spp. (13.3\%). Gram-negative bacteria and coliforms accounted for $10.2 \%$ (30 of 293) and 5.1\% (15 of 293) of all new IMI, respectively.

The crude dry period IMI cure risk for all quarters was $92.9 \%(522 / 562)$, which was similar in Lockout $(94.0 \%)$ and Orbeseal $(91.6 \%)$ groups. The final generalized linear mixed model estimated that Lockout quarters had similar adjusted dry period cure risk to Orbeseal quarters (94.4 vs. $91.8 \%, \mathrm{RD}:+2.6,95 \% \mathrm{CI}$ : $-1.8,7.1 \%$, Table 5$)$. The intraclass correlation coefficients for clustering of quarters within cows, and cows within herds were 0.30 and 0.15 . The final models for

Table 5. Final generalized linear mixed models (logistic) estimating the effect of internal teat sealant group (Orbeseal or Lockout) on quarterlevel dry period IMI dynamics ${ }^{1}$

\begin{tabular}{|c|c|c|c|c|c|}
\hline Item & $\begin{array}{c}\text { Adjusted risk } \\
(\%)\end{array}$ & $\beta$ & SE & $\begin{array}{c}\text { Risk difference }^{3} \\
(\%)\end{array}$ & $\begin{array}{l}95 \% \mathrm{CI} \text { of risk } \\
\text { difference }(\%)\end{array}$ \\
\hline \multicolumn{6}{|c|}{ Dry period IMI cure } \\
\hline Orbeseal & 91.8 & Referent & & & \\
\hline \multicolumn{6}{|c|}{ Dry period new IMI } \\
\hline Orbeseal & 13.8 & Referent & & & \\
\hline Lockout & 12.4 & -0.138 & 0.15 & -1.4 & $-4.3,1.6$ \\
\hline
\end{tabular}

${ }^{1}$ Orbeseal (Zoetis, Parsippany, NJ) and Lockout (Boehringer-Ingelheim Animal Health, Duluth, GA).

${ }^{2}$ Risk estimates using predicted/estimated marginal means.

${ }^{3}$ Risk difference estimates and 95\% CI were derived from generalized linear mixed models using predicted/estimated marginal means in Stata (also known as marginal standardization; version 15, StataCorp, College Station, TX). Final model included random intercepts for cow and herd. No fixed-effect covariates were included in the final model because there was no evidence for confounding when using the $10 \%$ change in estimate approach. Intraclass correlation coefficients for dry period IMI cure for cow and herd were 0.30 and 0.15 , respectively. Intraclass correlation coefficients for dry period new IMI for cow and herd were 0.29 and 0.14 , respectively. Intraclass correlation coefficients for IMI at calving for cow and herd were 0.32 and 0.16 , respectively. 

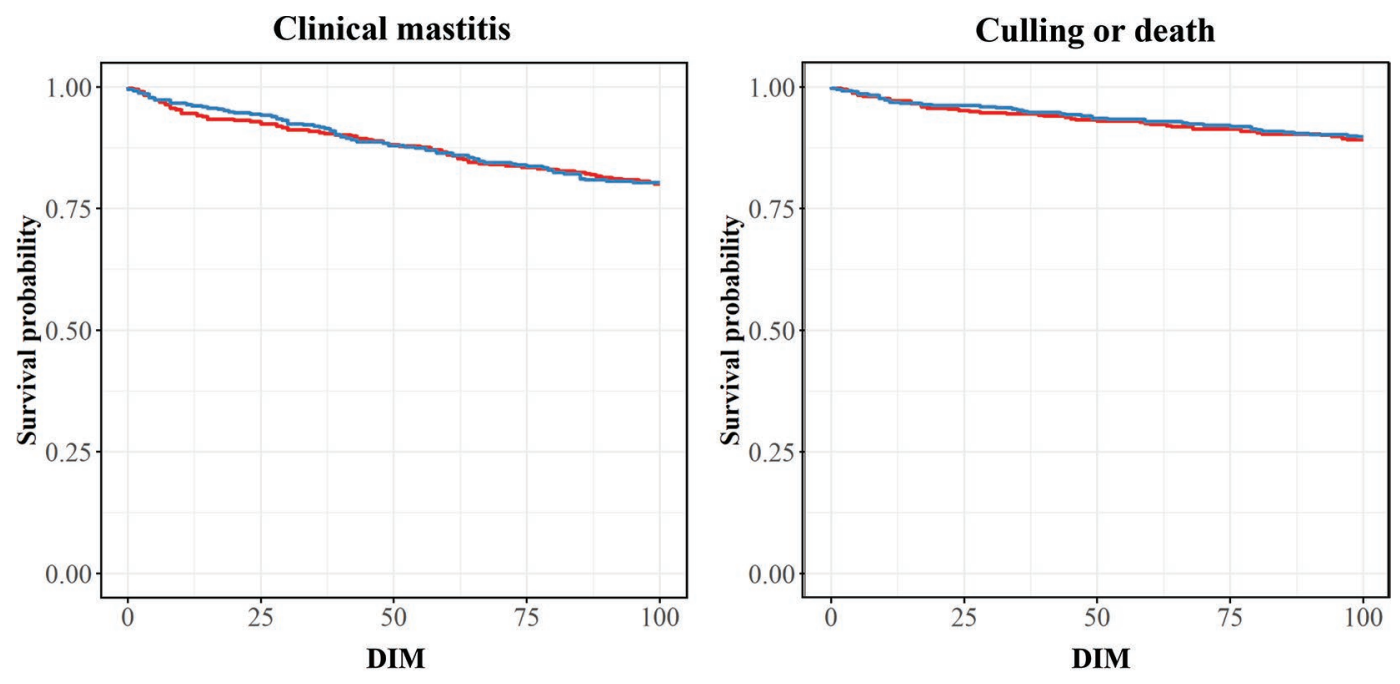

\section{- Orbeseal - Lockout}

Figure 3. Kaplan-Meier curves showing the incidence of clinical mastitis and culling/death events over the first $100 \mathrm{~d}$ of lactation for cows treated with 1 of 2 internal teat sealants [Orbeseal (Zoetis, Parsippany, NJ) or Lockout (Boehringer-Ingelheim Animal Health, Duluth, GA)] at dry-off. Log-rank tests for clinical mastitis and culling/death were $P=0.9$ and $P=0.8$, respectively.

dry period IMI cure and new IMI did not contain fixed effect covariates, as no evidence of confounding was observed when using the $10 \%$ change-in-estimate approach.

\section{Effect of ITS Group on Clinical Mastitis and Culling/ Death During the First 100 d of Lactation}

The crude 100-d clinical mastitis risk in all cows was $18.9 \%$ (158/834), which was similar in Lockout (19.0\%) and Orbeseal (18.9\%) groups. Kaplan-Meier survival curves also indicated that incidences for clinical mastitis and culling/death were similar between groups (Figure 3).
Risk ratio estimates from 10 univariable models for potential predictors of $100-\mathrm{d}$ clinical mastitis and culling/death risk are shown in Supplemental Table S3 (https://doi.org/10.3168/jds.2019-17884). The final Cox proportional hazards model found that Lockout cows had similar hazard rates to Orbeseal (referent) cows $(\mathrm{HR}=0.98,95 \%$ CI: $0.82,1.17$, Table 6$)$. The crude 100-d culling or death risk in all cows was $10.6 \%$ $(88 / 834)$, which was similar in Lockout $(10.3 \%)$ and Orbeseal $(10.8 \%)$ groups. The final Cox proportional hazards regression model found that Lockout cows had similar hazard rates to Orbeseal (referent) cows (HR $=0.94,95 \%$ CI: $0.66,1.35$, Table 6$)$. The final models for clinical mastitis and culling/death events did not

Table 6. Final Cox proportional hazards models for the effect of internal teat sealant group (Orbeseal or Lockout) on clinical mastitis and culling events during the first $100 \mathrm{~d}$ of lactation ${ }^{1}$

\begin{tabular}{|c|c|c|c|c|}
\hline Item & $\begin{array}{l}\text { Crude } 100 \mathrm{~d} \\
\text { risk }(\%)\end{array}$ & Hazard ratio $^{2}$ & Robust $\mathrm{SE}^{3}$ & $\begin{array}{c}95 \% \text { CI } \\
\text { of hazard ratio }\end{array}$ \\
\hline \multicolumn{5}{|c|}{ Clinical mastitis ${ }^{4}$} \\
\hline Orbeseal & 19.0 & Referent & & \\
\hline \multicolumn{5}{|c|}{ Culling/death ${ }^{4}$} \\
\hline Orbeseal & 10.8 & Referent & & \\
\hline Lockout & 10.3 & 0.94 & 0.184 & $0.66,1.35$ \\
\hline
\end{tabular}

${ }^{1}$ Orbeseal (Zoetis, Parsippany, NJ) and Lockout (Boehringer-Ingelheim Animal Health, Duluth, GA).

${ }^{2}$ Hazard ratio estimates were derived from Cox proportional hazards regression.

${ }^{3}$ Standard errors determined using a robust sandwich estimator to account for clustering of cows within herds.

${ }^{4}$ Backward selection (10\% change in estimates approach) resulted in no fixed effect covariates being included in the final model. 
Table 7. Final linear mixed models for the effect of internal teat sealant group (Orbeseal or Lockout) on test-day SCC and milk yield during the first $100 \mathrm{~d}$ of lactation ${ }^{1}$

\begin{tabular}{|c|c|c|c|}
\hline Item & $\mathrm{EMM}^{2} / \mathrm{LSM}$ & Difference & $95 \%$ CI of difference \\
\hline \multicolumn{4}{|c|}{$\log _{\mathrm{e}} \mathrm{SCC}^{3}\left[\log _{\mathrm{e}}(\right.$ cells $/ 1,000)$ per $\left.\mathrm{mL}\right]$} \\
\hline Orbeseal & 4.21 & Referent & \\
\hline Orbeseal & 42.76 & Referent & \\
\hline Lockout & 43.06 & +0.30 & $-0.69,1.30$ \\
\hline
\end{tabular}

${ }^{1}$ Orbeseal (Zoetis, Parsippany, NJ) and Lockout (Boehringer-Ingelheim Animal Health, Duluth, GA).

${ }^{2} \mathrm{EMM}=$ estimated marginal means.

${ }^{3}$ Fixed effect covariates included DIM at test, clinical mastitis during lactation of enrollment (yes/no), parity, peak SCC during lactation of enrollment. Intraclass coefficients for $\log$ SCC for cow and herd were 0.38 and 0.0, respectively.

${ }^{4}$ Fixed effect covariates included DIM at test, milk yield at last test. Intraclass coefficients for milk yield for cow and herd were 0.18 and 0.48 , respectively.

contain fixed effect covariates, as there was no evidence of confounding when using the $10 \%$ change in estimates approach.

\section{Effect of ITS Group on Milk Yield and SCC During the First $100 \mathrm{~d}$ of Lactation}

Effect estimates from univariable models for potential predictors of test-day $\log _{\mathrm{e}} \mathrm{SCC}$ and milk yield are shown in Supplemental Table S4 (https://doi.org/10 .3168/jds.2019-17884). The final linear mixed model for the effect of ITS group on $\log _{\mathrm{e}} \mathrm{SCC}$ is shown in Table 7. The estimated difference in $\log _{\mathrm{e}}$ SCC (Lockout minus Orbeseal) was $+0.06,95 \%$ CI: $-0.09,0.21$. The estimated marginal means SCC on the linear scale (i.e., adjusted geometric means in units of $10^{3}$ cells $/ \mathrm{mL}$ ) for each group were Orbeseal (67, 95\% CI: 58, 77) and Lockout (71, 95\% CI: 61, 82). Adjusted geometric mean estimates for each group, stratified by DIM category, are shown in Figure 4. The final model included fixed effects for DIM at test, clinical mastitis during the lactation of enrollment, parity, and peak $\log _{e}$ SCC during the lactation of enrollment. No interaction was observed between treatment group and test DIM $(P>0.05)$. Intraclass correlation coefficients for the clustering of tests within cows, and cows within herd were 0.38 and 0.00 , respectively. The final linear mixed model for the effect of ITS group on test-day milk yield is shown in Table 7 . The estimated difference in daily milk yield (Lockout minus Orbeseal) was $+0.30 \mathrm{~kg}$, 95\% CI: $-0.69,1.30$. The estimated marginal means for milk yield were Orbeseal (43 kg, 95\% CI: 32,53$)$ and
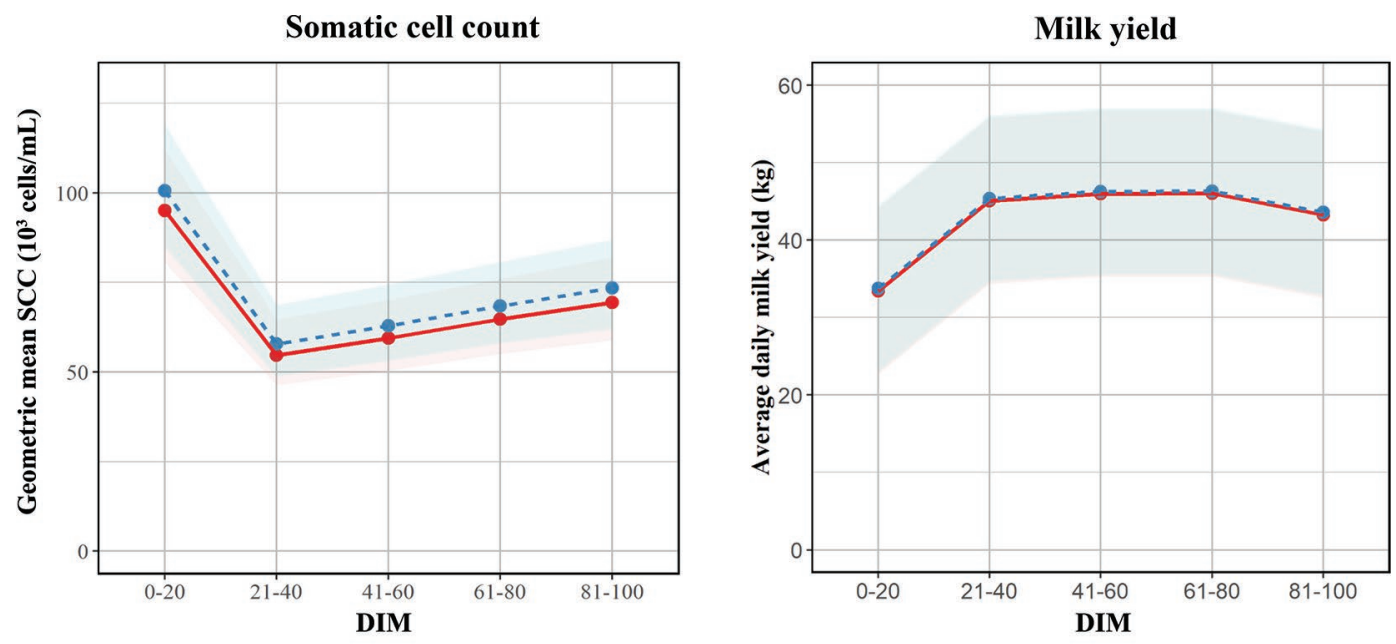

Orbeseal

Lockout

Figure 4. Estimated marginal means of test-day SCC and milk yield during the first $100 \mathrm{~d}$ of lactation for cows receiving 1 of 2 types of internal teat sealants [Orbeseal (Zoetis, Parsippany, NJ) or Lockout (Boehringer-Ingelheim Animal Health, Duluth, GA)] at dry-off. Colored shaded areas indicate $95 \%$ CI. No statistical interaction was observed between treatment group and DIM at herd test, which is why the curves are parallel. 
Lockout (43 kg, 95\% CI: 32, 54). Adjusted mean milk yields, stratified by DIM category, are shown in Figure 4. The final model included fixed effects for DIM at test and milk yield at last test. No interaction was observed between treatment group and test DIM $(P>0.05)$. Intraclass correlation coefficients for the clustering of tests within cows, and cows within herds were 0.18 and 0.48 , respectively.

\section{DISCUSSION}

\section{Prevalence of Quarter-Level IMI at Dry-Off and at 1 to 13 DIM}

The crude quarter-level prevalence of IMI at dry-off was $22.0 \%$, which is similar to recent multi-herd studies of late lactation cows in the United States, which found a prevalences of $21.1 \%$ (Rowe et al., 2019) and $25.4 \%$ (Rowe et al., 2020). The profile of pathogens causing IMI was similar between the current study and aforementioned studies, with gram-positive bacteria (646 of 663 infected quarters, 97.4\%), and NAS (474 of 663 infected quarters, $71.5 \%$ ) being the predominant cause of IMI. In addition, the prevalence of IMI caused by Staphylococcus aureus (0.4\% of quarters at risk) and gram-negative pathogens $(0.5 \%)$ was low. The quarterlevel prevalence of IMI at 1 to 13 DIM was $12.8 \%$, which is slightly less than other multi-herd studies of DCT protocols using ITS in the United States, which found risks of $23.0 \%$ (Rowe et al., 2020a), 23.0\% (Johnson et al., 2016), and $14.7 \%$ (Arruda et al., 2013). The profile of pathogens causing IMI at 1 to 13 DIM in the current study was similar to the aforementioned studies, with gram-positive (324 of 358 infected quarters, 90.1\%) and NAS being the predominant causes (225 of $358,62.8 \%$ ) and gram-negative pathogens being uncommon (32 of $358,1.1 \%$ ). Consequently, we believe the sample of cows in our study is likely to reflect the IMI pathogen profile of many North American dairy cows at dry-off and postcalving.

\section{Quarter-Level IMI Dynamics Over the Dry Period}

The overall crude dry period new IMI risk was $11.0 \%$ which is slightly less than other multi-herd studies of DCT protocols using ITS in the United States, which found risks of 20.1\% (Rowe et al., 2020a), 18.5\% (Johnson et al., 2016), and 13.3\% (Arruda et al., 2013). This variation in new IMI risk between studies is unsurprising, given that new IMI tends to vary between herds and within herds over time. For example, in the current study, the overall crude new IMI risk for each herd varied from 3.6 to $26.4 \%$, and the intraclass correlation coefficient for herd in the random effects model was
0.14 , indicating the $14 \%$ of the variation in new IMI was explained by herd-level factors. The finding is consistent with a recent study of selective DCT in 7 herds in the United States, which found that the quarter-level crude new IMI risk for each herd ranged from 4.0 to $29.0 \%$ and the intraclass correlation coefficient for herd was 0.15 (Rowe et al., 2020a).

The predominant pathogen groups causing new IMI in our study were NAS (mostly Staphylococcus chromogenes and Staphylococcus sciuri) and Bacillus spp. (Supplemental Table S2, https://doi.org/10 .3168/jds.2019-17884). Given that contagious spread of IMI during the dry period is unlikely, our findings indicate that these new IMI may be a result of teat exposure to bacteria in the dry cow environment. For example, Staphylococcus sciuri and Bacillus spp. have been isolated from bedding material of cows (Piessens et al., 2011; Patel et al., 2019). Furthermore, a recent study found that increasing Staphylococcus spp. counts in used organic bedding materials was associated with higher odds of NAS IMI in late-lactation cows (Rowe et al., 2019). However, the role of environmental reservoirs for Staphylococccus chromogenes has not been described, and instead, evidence suggests that this pathogen establishes cow-associated reservoirs, such as in skin or the mammary gland (Piessens et al., 2011). An alternative explanation for the apparently high new IMI risk for this pathogen may be due to persistent infections from the previously lactation that could have been missed at the sampling (false negatives) at dry-off. This is possible given that the sensitivity for detecting NAS from a single milk sample can be as low as 0.56 when using a threshold of $\geq 200 \mathrm{NAS} / \mathrm{mL}$ from a single milk sample (Dohoo et al., 2011b). The importance of controlling NAS and Bacillus spp. IMI during the dry period is currently unclear, as they are uncommon causes of clinical mastitis, and typically have modest effects on clinical mastitis risk and SCC (Green et al., 2002). Furthermore, observational research has found increased daily cow-level milk yield in early-lactation primiparous heifers infected with NAS IMI (Piepers et al., 2014). However this finding has not been replicated when evaluated at the quarter level (Valckenier et al., 2019).

The proportion of new IMI from pathogens that commonly use an environmental reservoir and cause clinical mastitis (i.e., environmental mastitis) was low. The proportions of new IMI (total is 293) caused by these pathogens were Streptococcus uberis (2.4\%), Streptococcus dysgalactiae (1.0\%), E. coli (2.7\%), and Klebsiella pneumoniae $(2.0 \%)$. Furthermore, the overall crude quarter-level prevalence of coliforms at 1 to 13 DIM was only $0.5 \%$. This low new IMI risk and consequential low prevalence of these pathogens at calving may 
indicate effective control of IMI over the dry period in the herds in this study.

The overall crude dry period IMI cure risk was $92.9 \%$, despite having used a narrow spectrum antibiotic (cloxacillin). This is likely because $97.4 \%$ of IMI present at dry-off were caused by gram-positive bacteria. This hypothesis is supported by clinical trials that have found no difference in dry period IMI dynamics in quarters treated with narrow and broad spectrum antibiotics at dry-off (Arruda et al., 2013; Johnson et al., 2016).

\section{Lockout and Orbeseal Had Similar Effects on Udder Health and Productivity}

This study found that Lockout treatment at dryoff consistently performed as well as Orbeseal, when comparing dry period IMI dynamics, early lactation clinical mastitis, culling and death, test-day SCC, and milk yield. This is evidenced by effect estimates and their $95 \%$ confidence intervals being close to 0 or 1 , for absolute (RD, difference in SCC or milk yield) and relative effect measures (HR), respectively. These findings indicate that producers could use factors other than efficacy, such as price, to decide which of these ITS products to use in their DCT program.

It is important to emphasize that this study evaluated the use of Lockout treatment in the context of a blanket DCT program. We decided to do this because approximately $80 \%$ of US dairy farmers currently practice blanket DCT (NAHMS, 2014), and most research evaluating the effect of Orbeseal on udder health has been conducted in the context of a blanket DCT program. However, Orbeseal has also been used in successful selective DCT protocols (Cameron et al., 2014; Rowe et al., 2020a,b) and in the precalving management of nulliparous heifers (Parker et al., 2007). Although we do not have reason to suspect that the comparative efficacy of Lockout to Orbeseal (i.e., equivalence) depends on the context (e.g., with or without antibiotics), we recommend that producers use caution when generalizing our results beyond blanket DCT protocols.

\section{Study Strengths and Limitations}

Study Design. One strength of this study was the large sample of quarters and cows, which provided precise effect estimates for many of the outcomes. However, our estimates for culling and milk yield outcomes were less precise, as indicated by wider $95 \%$ confidence intervals. Consequently, for these outcomes, we have less confidence about the difference in performance for Lockout and Orbeseal. We also used a variety of measures of udder health and productivity to compare
ITS groups, and our results were consistent across these outcomes. Furthermore, the statistical approach used to compare between treatment groups (equivalence hypothesis testing and confidence intervals) is a rigorous method for showing sameness between treatment groups. The margin of equivalence used in this study $( \pm 5 \%)$ is consistent with a noninferiority trial of DCT by McDougall (2010). We decided a priori that a difference of less than $5 \%$ units was, in our subjective opinion, sufficient proof for equivalence. However, we encourage readers to refer to the confidence intervals and decide for themselves if there is sufficient precision in the RD estimates to conclude equivalence between the 2 ITS products.

Internal Validity. Confounding and selection bias are unlikely sources of bias in our study. Our randomization method appeared to be effective, given the balance of herds and demographic details between treatment groups at baseline (Table 2). Furthermore, for most models, no covariates were found to change effect estimates by $>10 \%$ when they were removed from models, indicating that there was little or no measured confounding. However, this did occur for SCC and milk yield outcomes, which we believe was not due to a lack of balance between treatment groups at baseline (i.e., confounding), but more likely, due to very small effect sizes, which has been shown to increase the probability of variables being included in the final model when using a 10\% change-in-estimates approach (Lee, 2014). No evidence was observed for differential loss to followup, which included losses during the dry period due to death or culling and for antibiotic treatments in early lactation.

It is important to consider potential sources of information bias. The outcome variables in this study were based on IMI measurements taken at dry-off and at 1 to 13 DIM. However, milk culture is not $100 \%$ sensitive nor $100 \%$ specific in the diagnosis of IMI. One study estimated that the sensitivity and specificity of a single milk culture was 70 and $90 \%$, respectively (Dohoo et al., 2011a), which would lead to misclassification of some infected and uninfected quarters. We used colony-forming unit thresholds for NAS and Bacillus spp. isolates, which are likely to increase specificity at the cost of sensitivity (Dohoo et al., 2011b). It is also possible that sensitivity of IMI classification on farms A, C, and E could have been affected by the sampling strategy (i.e., postmilking collection; Sears et al., 1991). Another potential source of misclassification was from the lack of species-level diagnoses for some IMI, especially some NAS that were recorded as "Staphylococcus sp." This lack of detail was accommodated for in our definitions for new and cured IMI, which in theory 
could affect classification accuracy. If misclassification of IMI in quarters did occur for these reasons, we think it would have occurred equally in Lockout and Orbeseal quarters, which reduces the potential for misclassification bias. Furthermore, reduced sensitivity has a much less potent biasing effect than reductions in specificity (Haine et al., 2018).

External Validity. We believe that our research is relevant to a large proportion of American dairy farms because cows were enrolled from 5 herds located in the Southwest, Midwest, and Northeast dairy farming regions of the United States. Furthermore, the pathogen profiles observed in this study were similar to other recent surveys of cows at dry-off and in early lactation (Rowe et al., 2019, 2020a). However, the low crude new IMI risk in this study suggests that the level of challenge during the dry period was less than in the "average" US herd. It should also be acknowledged that herds were selected by convenience, and enrollment criteria were used. These criteria included an existing relationship with the University of Minnesota, Cornell University, or DairyExperts Inc., drying off at least 15 cows per week, on a monthly DHIA testing schedule and high quality clinical mastitis and culling records. Therefore, we recommend that readers use caution when generalizing these results to herds that are different to those enrolled in this study. It is also important to remind the reader that we compared Orbeseal and Lockout in the context of a blanket DCT program, which limits generalizations that can be made about the suitability of Lockout in other settings, such as selective DCT.

\section{Future Research}

Further research should be conducted to evaluate the efficacy of Lockout in other settings such as selective DCT and for nulliparous replacement dairy heifers. Similar research should be conducted to validate other ITS products that have recently entered the market.

\section{CONCLUSIONS}

In a multi-site, multi-herd, randomized, positively controlled equivalence clinical trial, we found that Lockout performed as well as Orbeseal for health indicators during the dry period (quarter-level new IMI risk, IMI cure risk, and IMI risk at 1 to 13 DIM) and during the first $100 \mathrm{~d}$ of lactation (clinical mastitis and culling or death risk and test-day milk SCC and milk yield). We conclude that producers could consider using either Lockout or Orbeseal as part of a blanket DCT program.

\section{ACKNOWLEDGMENTS}

The study investigators have no financial interest to declare. Funding for this study was provided by Boehringer-Ingelheim Animal Health (Duluth, GA). We are very grateful for the participation and tremendous cooperation by owners and staff at the 5 participating dairies. We also thank the technicians who assisted at each study site: California (Maria Amaral, Gema Camacho, Pablo Duque, Pallavi Nahata, Kruthika Patel, Maria Jose Perez, Cinthya Tovar, and Juanita Zaragoza; Dairy Experts, Tulare, CA) and Minnesota (Kelli Bowman, Joshua Brown, Pedro Paulo Cecillio Ferro, Chandra Dahike, Kaylan Risacher, and Victor Moro Taveira; University of Minnesota, St. Paul), as well as Francisco Leal Yepes (Cornell University, Ithaca, NY) who conducted fieldwork in New York. Author roles are as follows: S. M. Rowe was involved in local and multi-site coordination, fieldwork, laboratory work, data management, statistical analysis and manuscript preparation. S. M. Godden was involved in study conceptualization, herd recruitment in Minnesota, supervision of fieldwork and manuscript editing. A. Lago was involved in study conceptualization, local site coordination, fieldwork and manuscript editing. D. V. Nydam was involved in study conceptualization, herd recruitment in New York, fieldwork, and manuscript editing. E. Royster was involved in study conceptualization and manuscript editing. A. K. Vasquez was involved in fieldwork, local site coordination and manuscript editing. J. Timmerman was involved in laboratory work and manuscript editing. The authors have not stated any conflicts of interest.

\section{REFERENCES}

Arruda, A. G., S. Godden, P. Rapnicki, P. Gorden, L. Timms, S. S. Aly, T. W. Lehenbauer, and J. Champagne. 2013. Randomized noninferiority clinical trial evaluating 3 commercial dry cow mastitis preparations: I. Quarter-level outcomes. J. Dairy Sci. 96:44194435. https://doi.org/10.3168/jds.2012-6461.

Cameron, M., S. L. McKenna, K. A. MacDonald, I. R. Dohoo, J. P. Roy, and G. P. Keefe. 2014. Evaluation of selective dry cow treatment following on-farm culture: Risk of postcalving intramammary infection and clinical mastitis in the subsequent lactation. J. Dairy Sci. 97:270-284. https://doi.org/10.3168/jds.2013-7060.

Dingwell, R. T., K. E. Leslie, Y. H. Schukken, J. M. Sargeant, L. L. Timms, T. F. Duffield, G. P. Keefe, D. F. Kelton, K. D. Lissemore, and J. Conklin. 2004. Association of cow and quarter-level factors at drying-off with new intramammary infections during the dry period. Prev. Vet. Med. 63:75-89. https://doi.org/10.1016/j .prevetmed.2004.01.012.

Dohoo, I., S. Andersen, R. Dingwell, K. Hand, D. Kelton, K. Leslie, Y. Schukken, and S. Godden. 2011a. Diagnosing intramammary infections: Comparison of multiple versus single quarter milk samples for the identification of intramammary infections in lactating dairy cows. J. Dairy Sci. 94:5515-5522. https://doi.org/10.3168/jds.2011 -4486 . 
Dohoo, I. R., J. Smith, S. Andersen, D. F. Kelton, and S. Godden. 2011b. Diagnosing intramammary infections: Evaluation of definitions based on a single milk sample. J. Dairy Sci. 94:250-261. https://doi.org/10.3168/jds.2010-3559.

Edmonson, A., I. Lean, L. Weaver, T. Farver, and G. Webster. 1989. A body condition scoring chart for Holstein dairy cows. J. Dairy Sci. 72:68-78. https://doi.org/10.3168/jds.S0022-0302(89)79081-0.

Godden, S., P. Rapnicki, S. Stewart, J. Fetrow, A. Johnson, R. Bey, and R. Farnsworth. 2003. Effectiveness of an internal teat seal in the prevention of new intramammary infections during the dry and early-lactation periods in dairy cows when used with a dry cow intramammary antibiotic. J. Dairy Sci. 86:3899-3911. https://doi .org/10.3168/jds.S0022-0302(03)73998-8.

Golder, H. M., A. Hodge, and I. Lean. 2016. Effects of antibiotic drycow therapy and internal teat sealant on milk somatic cell counts and clinical and subclinical mastitis in early lactation. J. Dairy Sci. 99:7370-7380. https://doi.org/10.3168/jds.2016-11114.

Green, M. J., L. Green, G. Medley, Y. Schukken, and A. Bradley. 2002. Influence of dry period bacterial intramammary infection on clinical mastitis in dairy cows. J. Dairy Sci. 85:2589-2599. https://doi .org/10.3168/jds.S0022-0302(02)74343-9.

Greenland, S., and N. Pearce. 2015. Statistical foundations for modelbased adjustments. Annu. Rev. Public Health 36:89-108. https:// doi.org/10.1146/annurev-publhealth-031914-122559.

Haine, D., I. Dohoo, and S. Dufour. 2018. Selection and misclassification biases in longitudinal studies. Front. Vet. Sci. 5:99. https:// doi.org/10.3389/fvets.2018.00099.

Johnson, A. P., S. M. Godden, E. Royster, S. Zuidhof, B. Miller, and J. Sorg. 2016. Randomized noninferiority study evaluating the efficacy of 2 commercial dry cow mastitis formulations. J. Dairy Sci. 99:593-607. https://doi.org/10.3168/jds.2015-10190.

Kabera, F., S. Dufour, G. Keefe, and J.-P. Roy. 2018. An observational cohort study on persistency of internal teat sealant residues in milk after calving in dairy cows. J. Dairy Sci. 101:6399-6412. https:// doi.org/10.3168/jds.2017-13986.

Lee, P. H. 2014. Is a cutoff of $10 \%$ appropriate for the change-in-estimate criterion of confounder identification? J. Epidemiol. 24:161. https://doi.org/10.2188/jea.JE20130062.

McDougall, S. 2010. A randomised, non-inferiority trial of a new cephalonium dry-cow therapy. N. Z. Vet. J. 58:45-58. https://doi.org/ 10.1080/00480169.2010.65060.

Muller, C. J., and R. F. MacLehose. 2014. Estimating predicted probabilities from logistic regression: different methods correspond to different target populations. Int. J. Epidemiol. 43:962-970. https:/ /doi.org/10.1093/ije/dyu029.

NAHMS. 2014. Milk Quality, Milking Procedures, and Mastitis in the United States. USDA-APHIS-VS-CEAH-National Animal Health Monitoring System, Fort Collins, CO.

NMC. 2017. Laboratory Handbook on Bovine Mastitis. NMC, Madison, WI.

O'Connor, A. M., J. M. Sargeant, I. A. Gardner, J. S. Dickson, M. E. Torrence, C. E. Dewey, R. B. Evans, J. T. Gray, M. Greiner, G. Keefe, S. L. Lefebvre, P. S. Morley, A. Ramirez, W. Sischo, D. R. Smith, K. Snedeker, J. Sofos, M. P. Ward, and R. Wills. 2010. The REFLECT statement: Methods and processes of creating reporting guidelines for randomized controlled trials for livestock and food safety. J. Vet. Intern. Med. 24:57-64. https://doi.org/10 $.1111 /$ j.1939-1676.2009.0441.x.

Parker, K., C. Compton, F. Anniss, A. Weir, C. Heuer, and S. McDougall. 2007. Subclinical and clinical mastitis in heifers following the use of a teat sealant precalving. J. Dairy Sci. 90:207-218. https:// doi.org/10.3168/jds.S0022-0302(07)72622-X.

Patel, K., S. Godden, E. Royster, B. Crooker, J. Timmerman, and L. Fox. 2019. Relationships among bedding materials, bedding bacteria counts, udder hygiene, milk quality, and udder health in US dairy herds. J. Dairy Sci. 102:10213-10234. https://doi.org/10 $.3168 /$ jds.2019-16692.
Piaggio, G., D. R. Elbourne, D. G. Altman, S. J. Pocock, S. J. Evans, and C. Group. 2006. Reporting of noninferiority and equivalence randomized trials: An extension of the CONSORT statement. JAMA 295:1152-1160.

Piepers, S., P. Zrimsek, P. Passchyn, and S. De Vliegher. 2014. Manageable risk factors associated with bacterial and coliform counts in unpasteurized bulk milk in Flemish dairy herds. J. Dairy Sci. 97:3409-3419. https://doi.org/10.3168/jds.2013-7203.

Piessens, V., E. Van Coillie, B. Verbist, K. Supré, G. Braem, A. Van Nuffel, L. De Vuyst, M. Heyndrickx, and S. De Vliegher. 2011. Distribution of coagulase-negative Staphylococcus species from milk and environment of dairy cows differs between herds. J. Dairy Sci. 94:2933-2944. https://doi.org/10.3168/jds.2010-3956.

R Core Team. 2018. R: A Language and Environment for Statistical Computing. R Foundation for Statistical Computing, Vienna, Austria.

Rabiee, A. R., and I. J. Lean. 2013. The effect of internal teat sealant products (Teatseal and Orbeseal) on intramammary infection, clinical mastitis, and somatic cell counts in lactating dairy cows: A meta-analysis. J. Dairy Sci. 96:6915-6931. https://doi.org/10 $.3168 /$ jds.2013-6544.

Rowe, S., S. Godden, D. Nydam, P. Gorden, A. Lago, A. Vasquez, E. Royster, J. Timmerman, and M. Thomas. 2020a. Randomized controlled non-inferiority trial investigating the effect of two selective dry cow therapy protocols on antibiotic use at dry-off and dry period intramammary infection dynamics. J. Dairy Sci. 103. https: //doi.org/10.3168/jds.2019-17728.

Rowe, S., S. Godden, D. Nydam, P. Gorden, A. Lago, A. Vasquez, E. Royster, J. Timmerman, and M. Thomas. 2020b. Randomized controlled trial investigating the effect of two selective dry cow therapy protocols on udder health and performance in the subsequent lactation. J. Dairy Sci. 103. https://doi.org/10.3168/jds .2019-17961.

Rowe, S., S. Godden, E. Royster, J. Timmerman, B. Crooker, and B. Boyle. 2019. Cross-sectional study of the relationship among bedding materials, bedding bacteria counts, and intramammary infection in late-lactation dairy cows. J. Dairy Sci. 102:11384-11400. https://doi.org/10.3168/jds.2019-17074.

Sears, P. M., D. J. Wilson, R. N. Gonzalez, and D. D. Hancock. 1991. Microbiological results from milk samples obtained premilking and postmilking for the diagnosis of bovine lntramammary infections. J. Dairy Sci. 74:4183-4188. https://doi.org/10.3168/jds.S0022 -0302(91)78613-X.

Sprecher, D. J., D. E. Hostetler, and J. B. Kaneene. 1997. A lameness scoring system that uses posture and gait to predict dairy cattle reproductive performance. Theriogenology 47:1179-1187. https:// doi.org/10.1016/S0093-691X(97)00098-8.

Valckenier, D., S. Piepers, A. De Visscher, R. M. Bruckmaier, and S. De Vliegher. 2019. Effect of intramammary infection with nonaureus staphylococci in early lactation in dairy heifers on quarter somatic cell count and quarter milk yield during the first 4 months of lactation. J. Dairy Sci. 102:6442-6453.

Wasserstein, R. L., and N. A. Lazar. 2016. The ASA's statement on P-values: Context, process, and purpose. Am. Stat. 70:129-133. https://doi.org/10.1080/00031305.2016.1154108.

\section{ORCIDS}

S. M. Rowe @ https://orcid.org/0000-0001-8336-6523

S. M. Godden ๑ https://orcid.org/0000-0002-4438-0039

D. V. Nydam @ ittps://orcid.org/0000-0001-7717-4859

A. Lago (ㄴ) https://orcid.org/0000-0003-0380-0292

A. K. Vasquez (ㄴ) https://orcid.org/0000-0001-7639-0154

E. Royster ๑ https://orcid.org/0000-0002-8298-5581 